\title{
Student Attitudes toward Technology-Mediated Advising Systems
}

\author{
Hoori Santikian Kalamkarian \& Melinda Mechur Karp \\ Columbia University
}

\begin{abstract}
The literature on broad-access colleges suggests that low persistence and completion rates may be improved through better advising that employs a teaching-as-advising approach. While resource constraints have traditionally limited the ability of colleges to reform advising practices, technological advances have made it possible to implement technology-based advising tools, some of which can replace face-to-face services. Using focus group interview data from 69 students at six colleges, this study investigates students' attitudes toward technology-mediated advising. More specifically, we seek to understand how students' perceptions and experiences vary across different advising functions. We find that students are open to using technology for more formulaic tasks, such as course registration, but prefer in-person support for more complex tasks, such as planning courses for multiple semesters and refining their academic and career goals.
\end{abstract}

Keywords: technology, advising, iPASS, student supports, higher education

Kalamkarian, Hoori Santikian \& Karp, Melinda Mechur (2017) Student attitudes toward technology-mediated advising systems. Online Learning 21 (2) doi:

10.24059/olj.v21i2.918

\section{Introduction}

Amidst sweeping advances in information technology systems and increased higher education costs, a broad debate has emerged about the role of technology in higher education services (Blumenstyk, 2015; Tait, 2000). For some, the use of technology is framed as a "disruptive innovation" that has the capacity to displace many traditional business-as-usual processes in higher education (Blumenstyk, 2015). Proponents argue that replacing face-to-face services will bring cost savings and ensure that higher education continues to attract students who are increasingly comfortable and adept with technology. Critics maintain that using technology to displace processes that traditionally include substantial personal interaction with 
students, such as instruction and advising, will dilute the student experience (Blumenstyk, 2015; Gaines, 2014; Tait, 2000).

Recent focus on the role of technology in advising, in particular, mirrors the broader debate. While some argue that the increased use of technology will improve the information that students receive and strengthen student satisfaction (see, for example, Junco, 2010), others caution that advising is and ought to be dependent on human interaction (see, for example, Noonan \& Stapley, 2015). These divergent perspectives, however, do not sufficiently capture how technology may be used in higher education. Rather than fully replacing current systems, it is more likely that technology will increasingly be used in ways that coexist with traditional faceto-face delivery of services. In the domains of both instruction and advising, some thus argue that technology can be strategically integrated with face-to-face services in a way that optimizes the attributes of both mediums (Gaines, 2014). Put differently, technology may have a student support role to play alongside in-person interaction. It may be useful in some contexts for some functions but not others.

More research is needed on this topic, particularly in advising. Within the domain of technology-mediated teaching and learning, emerging research has begun to address the effects of increased use of technology. Recent empirical studies of online instruction have found that course grade and persistence vary across online courses depending on the subject area and the complexity of the course content; for example, studies have found that students struggle to persist in online versions of applied professions courses (Bambara, Harbour, Davies, \& Athey, S. 2009; Xu \& Jaggars, 2013). These studies contribute to a more nuanced understanding of the way technology may be used in higher education. Similar research is needed to better understand the potentially differentiated role that technology might play in technology-mediated advising services. It is important to consider the student perspective in such research. Proponents and critics of technology-mediated systems sometimes make assumptions about which platform for service delivery - technology-based or face-to-face-students prefer. Yet, empirical findings about the student perspective, particularly in the context of advising, remain largely absent (Gaines, 2014). Additional exploration of student attitudes may reveal important variation in student preferences regarding mode of delivery.

Using focus group interview data from 69 students at six colleges, the current study investigates students' attitudes toward technology-mediated advising. More specifically, we seek to understand how students' perceptions and experiences vary across different advising functions. We find that students are open to using technology for more formulaic advising services, such as course registration, but prefer in-person support for more complex undertakings, such as planning courses for multiple semesters and refining their academic and career goals.

This paper begins with a literature review of technology in higher education. Next, we present two conceptual frameworks that together guide our analysis of student attitudes toward technology for different types of advising and support functions. We then outline our findings and conclude with a discussion of implications for practice and for further research. 


\section{Background}

\section{Advising and Counseling in Broad-Access Colleges}

National college persistence and completion rates remain alarmingly low, particularly among low-income students and students of color at broad-access colleges (Bound, Lovenheim, \& Turner, 2012; Goodman, Hurwitz, \& Smith, 2015). We define broad-access colleges as public or not-for-profit private institutions that accept 80 percent or more of applicants, including community colleges (Doyle, 2010). For example, only about 30 percent of students who attend public two-year colleges full-time complete a credential (either an associate degree or a certificate) within three years of initial enrollment. Degree attainment is even lower among socioeconomically disadvantaged students (Aud et al., 2012; Karp, 2013).

The literature on broad-access colleges suggests that persistence and completion rates may be improved through institutional supports designed to foster student success, including advising and counseling. Theory suggests, and empirical research has found, that students are more likely to persist in college and complete a degree if they have clear goals, understand college processes, and engage with staff or other students on campus. In ideal circumstances, advisors can facilitate these conditions through personalized, holistic, and sustained guidance for students. Moreover, this ideal is achieved if advisors follow a "developmental" approach, meaning that they help students develop the self-awareness and problem-solving skills they need in order to clarify and fully commit to their aspirations (Karp, 2011). Put differently, advising that adheres to a developmental approach extends beyond information dissemination; instead, developmental advising supports student persistence by helping students develop the capacity to evaluate and make academic and vocational choices (Lowenstein, 2005).

Structural limitations, however, make it difficult for advising services at broad-access colleges to achieve this ideal. Advising and counseling centers at these institutions are severely underfunded and, as a result, understaffed. Advising loads typically range from 800 to 1,200 students for every advisor (Jaggars \& Fletcher, 2014; Karp, 2013). Moreover, broad-access colleges enroll a substantially larger proportion of socioeconomically and academically disadvantaged students compared with other types of institutions. These students need additional guidance and academic support, which further drains already limited staffing and financial resources (Karp, 2013; Karp, O’Gara, and Hughes, 2008).

Given these constraints, colleges often struggle to offer the comprehensive and integrated support services necessary to facilitate personalized, consistent advising. While they do often target incoming students, institutions typically do not have the capacity to require advising of all students and instead rely on students to self-advocate and to take initiative to make use of advising services when they feel it is warranted. In addition, colleges do not generally assign advisors to specific students (Karp, 2013; Karp et al., 2008). Advising sessions are also often limited in time, especially during peak advising periods such as registration period. Moreover, colleges commonly seek economies of scale by splitting apart advising functions, creating separate "services" or offices rather than providing holistic student support. For example, academic advising usually functions independently from financial aid advising, career counseling, personal counseling, and other areas of student support. Students often have to piece together information from different sources, and, even for academic advising, they are not necessarily able to meet with the same advisor in subsequent sessions. 
Under this structure, the advising experience often falls short of expectations, and the ideal advisor-advisee relationship is not established or maintained. Absent sustained interaction with the same student and the opportunity to engage with the student across advising functions, advisors are not able to offer personalized and holistic support. Instead, advising sessions often entail helping students more or less exclusively with the administrative function of registering for courses (Karp, 2013). As “registration clerks," however, advisors are not able to extend their engagement with students into the realm of developmental support. This support may be crucial in helping students learn to make wise, well-founded academic and career choices.

The literature on student perceptions of support services further underscores the limitations of typical advising practices (Grubb, 2006; Karp, 2011; Karp et al., 2008; Low, 2000). Survey and interview studies show that students generally rate their experiences with support services as negative to adequate (Jaggars \& Fletcher, 2014; Low, 2000). These studies suggest that students are dissatisfied with advising services because the information they receive during advising sessions falls short of the guidance they expect to get from advisors. Most students note that the advisors they work with primarily provide basic information about registering for courses and fulfilling graduation requirements, a description that aligns with the registration clerk analogy. While students note that it is important to receive this information from advisors, most students also expect more in-depth and personalized advising that includes career planning. Moreover, studies have found that students are, at best, only moderately satisfied with even the basic advising they do experience; several students in these studies reported receiving inaccurate information from advisors about registration and academic requirements (Karp et al., 2008; Low, 2000; Smith \& Allen, 2006).

\section{Technology-Mediated Advising}

To reform support services in the face of persistent resource constraints, several college administrators, policymakers, and education foundations are strongly advocating for the increased use of technology (Hornak, Akweks, \& Jeffs, 2010; Leonard, 2008; Moneta, 2005; Yanosky, 2014). For example, the 2014 White House summit on higher education focused on data- and technology-driven reforms to improve degree and certificate completion. During his remarks at the summit, President Obama advocated using technology to identify and support students who may be deviating from their path toward a degree (Felton, 2014).

Recently, technologies have emerged that offer robust information delivery and data analysis capabilities for student support services. These advising systems, sometimes referred to as Integrated Planning and Advising for Student Success (iPASS), seek to improve degree or certificate attainment by facilitating both intra-institutional coordination of student supports and data-driven academic decision-making for advisors and students (Yanosky, 2014). The growing suite of products in this space offers features that include:

- $\quad$ automated communication (institution-wide or with a subset of students),

- an institution-wide platform for identifying academically atrisk students, 
Student Attitudes toward Technology-Mediated Advising Systems

- interactive multi-semester course planning modules customizable for each student,

- shared staff access to notes from advising sessions (in accordance with privacy regulations), and

- integration of existing technologies, including data and course management systems.

This list suggests that iPASS products have the potential to make it easier for colleges and universities to coordinate across stakeholders within the institution, monitor student progress, and help students make wise choices (Yanosky, 2014). This paper refers to student support services that are offered through technology, including software or web-based hosts, as technology-mediated advising systems. This term is also used interchangeably with iPASS.

\section{The Impact of Higher Education Technology on Student Outcomes}

If and how iPASS technologies improve support services and, by extension, student outcomes, however, remain open empirical questions. Existing discussions of technologymediated advising primarily take place through commentaries, such as online blogs and newspaper or journal editorials, that are often not based on empirical findings (Hornak et al., 2010). A handful of colleges that have implemented one or more of these emerging technologies have conducted internal evaluations. These evaluations, however, have been limited both in terms of scope and methodology. Generally, the accompanying evaluation reports offer descriptions of specific technologies and share trends in student outcomes that may be related to, but are not causally linked to, these technologies (Oblinger, 2012; Phillips, 2014). Among these internal evaluations, Purdue University's study of the "Signals" early alert system offers the most methodologically robust framework. To evaluate this homegrown product, the university identified an experimental group of students who would receive alerts from Signals and compared their final course grades with those of students in a control group. Purdue University found that there was a lower proportion of Ds and Fs among the experimental cohort (Arnold \& Pistilli, 2010). Yet this evaluation is limited to the context of a specific course and does not extend to longer-term student outcomes.

One of the few studies of technology-mediated advising in the academic literature assessed the effect of student coaching on academic performance (Bettinger \& Baker, 2014). Coaches used a variety of media, including social network and text messaging as well as telephone calls, to communicate with treatment students over the course of two semesters. Coaches offered encouragement and individualized advice about managing academic and personal challenges while in college; comparison students did not receive individualized coaching but did have access to typical student support services at their college. Coaching positively impacted retention, highlighting the powerful influence that individualized, long-term support can have on student success. However, the study, by design, did not address if and how the technology-mediated structure of the coaching influenced the observed effect on student outcomes (either positively or negatively); the observed positive impacts could have been due to factors other than technology, such as the sustained relationship between student and coach. Additional research that specifically considers the technology-mediated delivery of advising would help to clarify technology's role in this process. 
Moreover, to better understand how technology-mediated advising shapes student outcomes, it is important to first understand what students think of engaging with advising resources through technology. Technology-mediated systems can only be effective if students are willing to use the systems; what students think and feel about them should therefore be considered when designing and implementing these systems. Moreover, students may have the most intimate knowledge of the support they need and how they would like to receive such support. As previously stated, technology advocates argue that because technology is often integrated into the fabric of everyday life among younger generations (Hornak et al., 2010; Joslin, 2009; Moneta, 2005; Stephens, 2007), students expect support to be delivered through technology tools. In these discussions, students are commonly referred to as "digital natives" (Leonard, 2008, p. 293), "the net generation" (Gaines, 2014, p. 44), and "the iGeneration" (Hornak et al., 2010), underscoring their high propensity to use technology. These notions of student comfort with technology, however, are largely assumed to apply to the advising context and are not sufficiently informed by speaking directly with students.

Findings from the few studies that have asked students about technology-mediated advising suggest that student attitudes may be more nuanced than technology advocates assume. In a survey of 167 undergraduate students, Gaines (2014) found that nearly half (47 percent) preferred to meet face-to-face with an advisor, while another one-third preferred to communicate with advisors through email. Similarly, in a study assessing the intake and orientation process at one community college, Jaggars and Fletcher (2014) found mixed responses from students regarding technology-mediated advising. While students preferred to meet face-to-face with advisors, they also indicated that they would like more access to information online. While their study highlights the complexity of student preferences, it is limited in scope to the orientation and intake components of advising. Additional research that further unpacks student attitudes toward technology across the spectrum of advising services, from course registration to education planning and career exploration, is needed.

While the literature on student attitudes toward technology specifically in the context of advising is limited, select studies have investigated what students think of online courses. The existing literature suggests that student preferences regarding online courses vary depending on the complexity of the subject. In one study (Jaggars, 2014), students who enrolled in both online and face-to-face courses expressed a preference for face-to-face instruction when they perceived the subject to be "difficult"; in the study, students generally referred to math and science courses as difficult. Students also felt that certain subjects were better suited for an online format compared with others. For example, students felt that the online format was not suitable for studying foreign languages because it would not allow students to practice speaking the language to each other. The variation in student attitudes toward online classes across subject areas suggests that student attitudes toward technology-mediated advising may also vary depending on the nature and complexity of the advising function.

\section{Conceptual Framework}

To examine how students would like to engage with advising and student supports, this study relies on two theoretical frameworks. First, we take a particular point of view on the optimal approach to advising in broad-access colleges, that of "advising as a form of teaching" (Appleby, 2008). Second, we use Tait's (2000) framework to unpack the different types of 
advising and student support functions in which advisors and technology tools engage. The first framework enables us to ground our analyses in a specific theoretical point of view that underscores the foundational nature of advising in encouraging student success; the second enables us to explore which pieces of advising-as-teaching may be best suited to various methods of provision.

Advising as a form of teaching is the dominant view of advising among education theorists, and it aligns with best practice guidelines put forth by the National Academic Advising Association, the leading professional association for college advisors (Appleby, 2008). The advising-as-teaching approach defines academic advising as a relationship between an advisor and an advisee that parallels the relationship between an instructor and a student. Both effective teaching and effective advising entail not only disseminating information, but also cultivating students' higher-order reasoning skills. Exemplary instructors teach students analytic skills that they can then apply across subjects and contexts (Appleby, 2008; Lowenstein, 2005; Moore, 1993). Exemplary advisors guide students to develop the problem-solving and higher-order cognitive skills they need to successfully navigate their postsecondary trajectory (Appleby, 2008; Lowenstein, 2005). Ultimately, both effective instructors and effective advisors help students make meaning of their educational experiences. Instructors guide students to see connections between assignments within a class and thereby construct a cohesive understanding of the material. Similarly, advisors help students clarify the logic connecting the disparate courses that together comprise their overall college curriculum (Lowenstein, 2005).

To facilitate the development of higher-order skills, advising sessions should mirror the "active learning" classroom model. According to this model, students develop analytic skills by engaging directly with the material instead of being passive recipients of information. Therefore, advisors ideally guide students through an interactive exchange to explore and evaluate alternative pathways and clarify education and career goals (Appleby, 2008; Lowenstein, 2005; Moore, 1993). Feedback from the advisor prompts the student to reflect, evaluate, and ultimately, arrive at a decision. By facilitating students' active participation in decisions about their education, advisors help students develop the skills they need to make subsequent decisions about their education (Appleby, 2008; Lowenstein, 2005). Theoretical discussions assume that the advising occurs primarily in a face-to-face context (Appleby, 2008; Lowenstein, 2005).

Though advising-as-teaching is the preferred approach of professional advisors, the realities of life in open-access colleges described earlier make this approach challenging to implement. To facilitate an interactive relationship with students, advisors need to invest substantial time and resources in working with each student. For example, Appleby (2008) offers a guide for designing an advising curriculum that calls for scheduled face-to-face advising sessions with a "question and answer" format; in addition, advisors are encouraged to ask questions to prompt less expressive students. Financially constrained and understaffed colleges struggle to allocate the resources to structure advising sessions in this staff-intensive format. Technology products may help institutions move closer to an advising-as-teaching approach by reducing the burden on advising services. For example, products that allow faculty to flag academically at-risk students allow advisors to more quickly and effectively identify students who need additional support.

Advising-as-teaching emphasizes the need to teach higher-order thinking skills in navigating postsecondary education. However, not all advising functions necessarily require 
extensive higher-order thinking. Some advising activities may require less intensive instruction and therefore may rely less heavily on the advising-as-teaching framework. To differentiate between advising functions, this study applies Tait's (2000) conceptual framework for types of student support. This framework recognizes higher-order support functions and thus aligns well with the advising-as-teaching principle. However, this framework also differentiates among the various types of activities in which advisors and students engage and is therefore more representative of the realities of day-to-day advising activities. Moreover, this framework is widely used in the design of support services in the context of online and distance education, which parallels the technology-mediated context of this study.

Tait (2000) identifies three categories of student supports in online courses: systemic, affective, and cognitive. Systemic support involves helping students navigate administrative tasks; in advising, this type of support includes clerical functions such as helping students register for courses. Affective support, both broadly and in the context of advising, involves strengthening students' confidence and sense of self-efficacy by creating an encouraging environment. Finally, cognitive support includes facilitating learning through supplemental instruction and feedback. In advising, cognitive support involves helping students develop the skills to make decisions about their postsecondary pathway and achieve clarity in their educational and career goals. Together, these two frameworks allow us to investigate when and why students prefer technology-mediated support services.

\section{Data and Method}

This study addresses the following research questions:

1. What are students’ attitudes toward technology-mediated advising services?

2. How do students' attitudes toward technology-mediated advising services vary across different types of advising functions?

3. What are the implications of students' attitudes toward technologymediated advising for the organization and promotion of these systems?

The data presented in this study come from student focus group interviews conducted at six colleges that vary in urbanicity and sector type. Our sample includes two small non-urban community colleges, two urban community colleges, one mid-sized urban state college, and one rural mid-sized state college. The mid-sized urban college is also categorized as an historically black college or university, or HBCU. An HBCU is a college or university founded before 1964 for the primary purpose of serving African American students. There are currently 105 certified HBCUs in the country (U.S. Department of Education, n.d.). Sites were selected from volunteer colleges interested in deploying iPASS technologies. This study is part of a larger analysis of iPASS implementation at participating colleges.

To collect data, the research team conducted three-day site visits to each college during fall 2013. Over the course of all six visits, we conducted 18 focus groups with 69 students. 
Students were invited to participate in focus groups through a mass email sent by each institution's office for student services. All students who were interested in participating were asked to contact the research team directly by phone or email. Students were selected on a firstcome, first-serve basis. All participating students received a \$25 retail gift card.

In addition to the focus group interview, all students who participated completed a brief background questionnaire; we use data from this questionnaire to calculate descriptive statistics. Our sample included 25 male and 44 female students. While students in our sample ranged from 16 to over 60 years old, 75 percent were 18-25 years old. A large majority (81 percent) of the students in our sample attended college full-time; the remaining 19 percent of students were enrolled part-time at the time of data collection. Our sample included both new and more advanced students; 43 percent of students were in their first semester, while 57 percent were in their second or subsequent semesters. It is important to note that the survey data are not linked to focus groups; as a result, we cannot disaggregate the survey responses based on insights shared during focus group interviews.

Table 1

Demographics of Sample Compared with National Statistics

\begin{tabular}{lcc}
\hline Characteristics & $\begin{array}{c}\text { Our Sample } \\
(\mathbf{n = 6 9 )}\end{array}$ & $\begin{array}{c}\text { National Statistics } \\
\text { (IPEDS 2012) }\end{array}$ \\
\hline Female & $64 \%$ & $57 \%$ \\
$\begin{array}{l}\text { Traditional-aged } \\
(\mathbf{1 8 - 2 5 )}\end{array}$ & $75 \%$ & $61 \%$ \\
Full-time & $81 \%$ & $39 \%$ \\
\hline
\end{tabular}

The demographic make-up of our sample aligns moderately well with national demographic characteristics for community college students. According to IPEDS (U.S. Department of Education, Institute of Education Sciences, National Center for Education Statistics, 2012), a majority of community college students nationally are women. However, while a majority of students in our sample attended college full-time at the time of data collection, nationally, slightly less than 40 percent of community college students attend fulltime. The overrepresentation of full-time students in our sample reflects the challenges with reaching and engaging part-time students in campus and related activities. It is also important to note that, according the existing research, students often switch between part-time and full-time status throughout the course of their tenure at community colleges (Crosta, 2014); therefore, the limitations posed by the overrepresentation of full-time students in our study are somewhat mitigated.

The student focus groups were designed to capture how students approached academic decisions and the extent to which advising resources contributed to their decision-making process. During semi-structured interviews students were asked to describe their experiences in each of five areas: course selection, course registration, major selection, multi-semester planning, and academic interventions from the college. Once students had described their general approach 
in each of these areas, we probed about their use of various technological tools. For example, students who indicated that they planned for multiple semesters were asked to describe how they figured out which courses they needed to take and to what extent they used online or other electronic tools. We also probed for opinions about technology-mediated advising as the conversation warranted. Typically, a few students from the group described their experiences at length, and others noted if and how their experiences compared with those described by their peers.

Focus group transcripts were coded and analyzed using Atlas.ti software. A preliminary code list was developed based on the research questions guiding the overarching study and initial impressions about possible themes. We organized codes into four overarching categories: context, service practices, service process, and service structure. Context codes captured student and institutional needs. The service practice category included 15 codes, one for each identifiable service function such as course selection, registration, and major selection. Service process codes specified whether students completed the task independently or with assistance from institutional support services, including iPASS products. Finally, the service structure codes captured the organizational setup of support services. Four rounds of test coding were conducted to refine the preliminary codebook. Inter-rater reliability was established through the test coding process and ongoing coding reviews conducted by the project lead for every fifth transcript; moreover, coders discussed codes for particular passages during weekly coding meetings.

After all of the documents were coded, we used Atlas.ti tools to identify themes relevant to the focus of this paper. This process included running queries that identified concurrence of codes, in particular across the service practice and service process categories. For example, to understand when students used technology, including iPASS products, to plan their coursework, we queried the concurrence of "service practice-multi-semester planning" and "service process - technology-system-wide.” We read query outputs thematically to identify emerging themes and organized themes in an Excel spreadsheet, with each row representing a different theme and each column displaying a quote indicative of the corresponding theme. We used our conceptual framework to guide our analysis; where appropriate, we reorganized our emerging ideas into broader themes that mapped student preferences to the three categories of advising (systemic, affective, and cognitive) identified in our framework. For example, under the broad category of "systemic support" we organized excerpts by three themes: support for basic procedural questions, feedback on course logistics, and confirmation to ensure accurate course selection and registration.

It is important to note that to maintain the anonymity of the students who participated in our study, we did not record any names. Our transcriptions thus do not specify which student made which comment. This presents methodological limitations. We are not able to trace the comments of specific students over the course of the interview. We are also not able to count the number of students who make a specific point across our sample.

\section{Findings}

Our data address both students’ attitudes toward advising generally and their perspectives on in-person and technology-based delivery of services. Overall, we find that students in our study sought an interactive relationship with advisors that is characteristic of the advising-asteaching approach; in particular, students wanted to learn from advisors how to approach more 
complex educational decisions, such as planning courses and preparing for a career. Our data also indicate that students' attitudes toward technology-mediated advising varied depending on the advising context. In particular, students preferred in-person interaction with an advisor for cognitive support, but expressed more willingness to receive administrative and affective support through technology. The remainder of this section elaborates on these findings.

\section{Students Preferred an Advising-as-Teaching Approach}

One theme that emerged from our data is that students tended to want to rely on advisors to help them make the most of their college experience. For example, one student said, "And if it just becomes all self-motivated, all you-do-it-yourself, then [you're] just going to be stuck on a plateau, where you can reach [but] you can't exceed over it.” The student's concern reflects the perspective that, as the advising-as-teaching approach suggests, advisors help students develop their higher-order reasoning skills and make sense of their educational experiences.

Students also preferred an interactive relationship with an advisor, rather than a didactic or one-way information exchange. The types of advising sessions that focus group participants recounted as positive experiences were those in which advisors and students engaged one another in such a way that the students were not passive recipients of information but rather active participants in the relationship. In one focus group, for example, students described working with an advisor to select courses for the upcoming semester. When asked how confident students felt about the courses that advisors suggested, the students emphasized that they felt at ease with the selected courses because the decision came from an interactive exchange with the advisor.

Q: And how confident are you in the decisions they make for you?

Student 1: Pretty confident, confident because they discuss it with you.

Student 2: Right, it's not like they are making the decision for you. They are making the decision with you.

Student 3: Yeah, they don't just tell you, "Well you need to take

English”... They will say that you need to take English because you have to have [taken] it before blah, blah, blah.

Student 1: And then they will say, "Do you want to take English now?” It's the variety of questions that they ask you that will get you in the right direction that you want to go.

In contrast, advising sessions during which the advisor did not facilitate the students' involvement in educational decisions left students feeling unsettled. The students' descriptions of these experiences reflected their preference for a more interactive relationship with advisors. The contrast between advising-as-teaching and a more one-dimensional approach is exemplified in these two quotes from a single student who experienced both approaches. In reference to the first advisor he worked with during the first semester, the student said:

He sat down, he looked at my schedule and all the classes I needed to take. He was like, "You need to take this, this, and this," and I was like, "That's 
a lot on my plate.” ... He was like, "Well it has to be done,” [and so] I was like, "Yeah okay.” But he really wasn't that helpful. He just told me everything that I need to take and that was it.

He described his frustration with an advising approach that did not involve him actively. In contrast, he described a second semester advising experience by saying,

So when I went to my advisor she gave me options, she said, "You have to take this [course], but here [are] other courses [to take] in order to get your hours up.” So I liked that I could choose, because first semester ... it was just kind of chosen for me. Which is understandable, because it is just your core classes. But, I mean, I want to at least know what's going on.

The student's comparison of the two sessions suggests that the student preferred the second session not just because he disliked having to take preset courses. Rather, his use of phrases such as "he just told me" and "I want to at least know what's going on" indicates his preference for being an active participant in the advising process.

Our data also indicate that students preferred an interactive relationship with an advisor because they believed that an interactive approach would help them learn the skills they need to manage educational tasks and decisions moving forward. For example, students often told us that they wanted to be able to perform some advising functions, like course selection, independently as they progressed through college. However, many described not feeling prepared to do so. Students' concern that they were not prepared to make future educational decisions usually came up in the context of advising sessions that had not been interactive. They noted that without interacting with an advisor, they were unable to learn how to undertake advising tasks for themselves.

One first-year student's comments exemplified this point of view when she described feeling confused about selecting and registering for courses for the second semester because during orientation the previous summer, advisors completed these tasks without fully engaging the students. She said:

Well I came, you know, did the little tour I guess and sat in a classroom and the teacher made our schedules. It was that easy. [Laughing]. It was. Which, I mean, it was no help looking back at it, because now the time is coming up where it's like, okay, it's time for you to make your schedule on your own. You don't have nobody there spoon-feeding it to you, because [in the prior situation] this man sat there and he was like, well you need to take this and this, type this number in, okay there's your class right there. Basically, he did all the work for us, and now I'm kind of lost on what to do coming up for next semester's classes.

In this example, the student indicated that she did not learn how to approach course selection and education planning during orientation because the advisor did not teach her these skills during the session. The student's criticism suggests that the student would have preferred to more actively participate in advising sessions in order to learn from the experience. 


\section{Advising-as-Teaching Was Perceived as Particularly Important for Cognitive Support Tasks}

Although students preferred advising-as-teaching interactions in general, our data indicate that they particularly did so for tasks that are more complex in nature. Such tasks require higher-order reasoning and align with Tait's (2000) conception of cognitive support. According to Tait, cognitive support involves helping students develop decision-making skills and identify clear aspirations. In the context of advising, tasks that are more complex or cognitive in nature include planning courses for multiple semesters in advance and selecting a program of study or career path.

The focus group data underscore students' beliefs that cognitive tasks require an approach that approximates teaching. Students in our sample were concerned that the knowledge they had for making complex education decisions was limited in ways that they were not aware of, making it exceedingly difficult for them to address possible informational deficiencies. Similar concerns among students have been revealed in research on the transition from high school to college. In a study by Karp and Bork (2012), new college students described relying on advisors to illuminate these unknowns as a means to enhance how they thought about their postsecondary pathways, which is consistent with findings in the current study.

In our study, one student's description of her interactions with two advisors reflects this perspective. The student said:

When somebody really looks at you and when they are answering questions that you didn't even think to ask, that means that they are already in the mindset of getting you where you want to go. There has been a lot of time [names of advisors] both have said things to me that I didn't even think about in terms of my course and my path here and things that are going on.

In this example, the student relied on guidance from advisors to work through the intensive task of clarifying a postsecondary path. The student further noted that advising assisted in this process by illuminating unknowns through interactive questioning, a description that reflects the advising-as-teaching approach.

Students in our study often expressed a preference for the developmental and interactive approach characteristic of the advising-as-teaching framework in reference to particular kinds of advising sessions - those that addressed education planning. This is probably because such activities involve substantial cognitive support. Education planning involves receiving feedback on one's choices and the opportunity for advisors to teach students how to engage in planning independently. Our data indicate that students felt that their experiences were enhanced when advisors engaged in teaching activities during program planning sessions.

Students also indicated that they preferred when their advisors offered feedback on their postsecondary choices. For example, one student described her experience discussing potential programs of study with two advisors during two different advising sessions. During the first 
session, the student felt the advisor did not offer sufficient feedback. "It was like I was telling them," the student said. "They weren't telling me.” The student felt that the session was "not helping me at all" because the advisor primarily described program requirements instead of engaging the student in an interactive discussion of her goals. The student said,

It’s like I’m saying, “Okay I want to do nursing,” and they were like, “Okay, nursing. You'll have to do this.” They don't say, "What are you trying to do in nursing? Where are [you] trying to go?” so [that] they can advise me better.

In contrast, during a subsequent advising session, another advisor guided the same student toward thinking about the relationship between a different program of study and a career path. The student noted, "[The advisor] actually said, 'Well, prelaw-what are you trying to do with it?"' The advisor and student discussed a potential career in law and politics. The discussion, according to the student, integrated "my knowledge of what I knew and what [the advisor] knew, and it made it a little bit better for me.” The variation in the student's experience across the two sessions suggests that the student got more out of the interactive discussion about her program of study that included feedback from the advisor.

In addition to their preference for receiving feedback on potential choices for programs of study, students also indicated a preference for interactive advising sessions around planning courses for current and subsequent semesters . According to students, given the complexity of this task, an advising-as-teaching approach is especially beneficial for helping them develop the skills to plan independently. Students often sought confirmation from advisors that they had selected courses wisely. This included ensuring that courses met program requirements and represented an appropriate workload. Confirmation from advisors served to affirm students' approach to planning and their confidence in selecting courses independently. For example, one student described planning his course schedule confidently after completing the process for the first time with an advisor. During the first meeting, the student made "sure everything was good," meaning that he understood what he and the advisor had planned together. Subsequently, the student felt more confident selecting courses on his own.

\section{Students Were Skeptical of Technology-Based Delivery of Cognitive Supports}

In addition to the general advising preferences described in the previous two sections, our data also revealed student attitudes specifically toward the technology-based platforms for student supports. The vast majority of students in our sample felt that technology-based advising tools could not provide them with the personalized feedback and developmental instruction that they believed was essential, especially for advising tasks that are more cognitive in nature. For example, as previously noted, students are often uncertain about how to approach college, and they value advising interactions that teach them how to plan their programs of study and otherwise be successful in a collegiate environment. Students in our study indicated that these types of cognitive advising tasks are ill-suited to technology; one student explained this by saying, "But [for] a freshman who doesn't know what he wants to have, what kind of major, I mean, [advising technologies are] going to be quite different for him. I most probably think that person would definitely come to an advisor." Another noted that technology-based advising would work "only if you actually know what the heck you're doing." In other words, if students need advisors to teach them, they do not believe that technology can take the place of a person. 
Moreover, students explained that they were concerned that technology-based advising would not facilitate the type of personalized feedback that is available in an in-person setting. As one student put it, it is difficult to "get an opinion" online, but "in- person you can definitely get an opinion about the history of-has this course transferred, has it not, or things like that." Another student offered a similar explanation for his skepticism of technology-mediated systems. When asked how he felt about education planning using these systems, the student said, "I often have questions about how well my background really fits in with the course content." In this example, the student felt that technology alone could not field questions about his background; the student wanted to be able to speak with an advisor in order to ask specific personal questions such as, "I took my SATs in 1977, does that matter?"

It is important to note that the students in our sample did not discount technology-based tools for cognitive support entirely, and they tended to agree that these systems were engaging and more efficient than meeting with an advisor, which often required standing in long wait lines or an extra trip to campus. As one student said in reference to the benefits of using an online education planning tool, "I don't want to waste my time here-coming to school when I don't have to. I can do it at home.” However, the logistical benefit of working independently online was enticing only for students who had already learned how to navigate these cognitive-rich tasks. According to the same student, for example, the online planning tool effectively facilitated self-advising "if you can figure everything out," such as how to manipulate the system to identify the courses that are needed for a program of study.

Several students also suggested that while they were skeptical that technology-mediated systems alone could provide cognitive supports, these systems could, they felt, enhance a student's in-person interaction with an advisor. These students explained that the information available through the technology could inform a student's discussion with an advisor. For example, one student felt that it was inaccurate to rely exclusively on his university's technology-mediated advising system for predicting his likelihood for success in a course because the system used ACT scores to provide a prediction, which he found to be limiting. However, the student noted that the system served as a useful tool to inform the conversation between an advisor and an advisee. Advisors reference the system and elaborate on what the system says about a student's likelihood to pass a course with what they themselves know about the course. As the student put it, "If [advisors] ... look at the paper and they're like, 'This is a hard class. If you don't do this, this, and that, you are going to fail it. ... Let's think about that for a second." In this example, the student explained that the interactive engagement with the advisor allowed for individualized discussion of the student's capabilities and feedback for succeeding in the course. Although the technology-mediated system was not able to provide this type of interactive relationship, the predictions made by the system guided the advisor's instruction.

Similarly, a number of students suggested that technology-mediated systems could empower students to take a more active role in discussions with advisors, thus encouraging cognitive advising tasks. Students reported that with technology-mediated systems they could do more pre-planning before an advising session, using information available online to guide the questions they ask during their meeting. They indicated that this might help them learn more during the advising session by helping them focus on what they want to take away from the interaction. These students preferred having both formats of advising available and suggested using them in conjunction with each another. 


\section{Students Preferred Technology-Based Delivery of Systemic Supports}

Although students were skeptical of technology-based delivery of cognitive supports, the students in our sample tended to agree that technology-mediated systems could provide a convenient and efficient way to deliver systemic support. Recall that in Tait's (2000) framework, "systemic support" refers to administrative tasks, including the clerical function of registering for courses each semester. Students reported that they preferred using technology to complete administrative tasks that do not require extensive feedback from advisors. As one student said in reference to the college website, "Everything is there-the email, the phone, their extension number, the teachers, department under events and news. You know if the college is closed, or [can find out important dates and information] if you don’t have your handbook.”

In addition to accessing general information about the college, other students also indicated that they used technology to find answers to more specific, but still simple questions. For example, one student described using technology to research answers to "silly questions," such as the date for a financial aid check disbursement. The student said, "I didn't really want to ask that from my advisor. So I looked it up on the website.” Moreover, the student noted that it was more convenient to look the answer up online than to "take the time to call and ask, and then have to have them look it up.”

Moreover, several students reported that they either register for courses online without the support of an advisor or would be willing to do so after basic training on the registration system. While researching and selecting which courses to take (education planning) is more cognitive in nature, course registration refers to the technical function of actually signing up for courses and is largely an administrative task that does not require instruction from an advisor. Students indicated that online registration could be "easy and quick." Although some students said that training was necessary to use the registration system, these students said that basic training such as, as one student suggested, “a 30-minute little demo thing” would suffice.

While students generally agreed that in theory technology-based support for clerical functions including registration would be appropriate, not all students in our sample were comfortable registering online in practice. These students, however, were primarily concerned that technical glitches could compromise the process. When asked, however, if feedback from the technology indicating that the registration process had been completed correctly would provide the necessary reassurance, students agreed that this feedback would suffice.

\section{Preferences Were Mixed Regarding Technology-Mediated Affective Support}

While students tended to agree that technology can sufficiently facilitate systemic support, student perspectives on technology-mediated advising for affective support were more mixed. As previously noted, "affective support” in Tait's (2000) framework refers to creating a welcoming and encouraging environment.

Most of our data on technology-mediated affective support come from a subset of questions that asked students about early alert technology solutions. Students in our sample offered varying reactions to early alert systems. Some students considered the early alert system an effective mechanism for offering affective support. As one student put it, "[The early alert] shows that they care about you. And [that they] want to know what is going on with you. It 
might be something serious. So, I think that's a good thing.” Other students felt the alerts were an unwelcome overreach. As one student put it, "It's just ... almost scary, like spies are stalking you all the time and let you know, 'Oh you didn’t come to class ... this day.”’

Our data indicate that student perspectives on early alert systems depend in large part on the content and framing of the messages that such systems provide students. While students do not necessarily require the intensive support of the advising-as-teaching approach for affective support, to successfully encourage students, our findings suggest that messages from technology tools must retain a personal and interactive quality. One student, for example, emphasized the importance of a non-judgmental tone, stating that the early alert message should "give the student a feedback, without making them feel guilty." Students also emphasized the importance of a personalized message aimed at identifying the student's specific challenge and motivating the student to engage with the college community. One student who made this point said that it would be helpful if the technology "facilitated communication and said: "Are you not liking this course? Are you thinking about changing or just pulling out of the course early?'” These student perspectives suggest that technology-mediated system messages from the college could serve to effectively orient and encourage students if the messages serve as a platform for a more interactive relationship with an advisor.

\section{Discussion and Conclusions}

Overall, our analysis lends support to the widely held view that advising-as-teaching is the optimal approach to advising in broad-access colleges. The student preferences outlined in this paper show that students value this approach to advising. In addition, our analysis contributes to the literature on technology-mediated advising by empirically validating the utility of Tait's (2000) categories for student support services in a technology-mediated setting. Systemic, affective, and cognitive support functions appear in our sample students' discussions of their advising experiences and preferences, suggesting that Tait's framework is apt. Moreover, although Tait frames these conceptual categories for use in understanding supports in online courses, our analysis suggests that the framework applies broadly to support services in any technology-mediated higher education context.

Together, the advising-as-teaching paradigm and Tait's (2000) framework for support services work well as a means for exploring student preferences about advising. While students in our study generally preferred the advising-as-teaching approach, disaggregating their preferences using Tait's three categories illuminate variations across different advising functions. Our study demonstrates that students do not possess an "all or nothing" attitude toward technology's potential role in support services. Instead, it suggests that technology alone may be sufficient for some support functions but that it works best as a supplement to in-person advising in other contexts.

Our findings suggest that institutions may want to consider optimizing technologymediated systems by targeting technology tools for less complex advising tasks, thereby creating space for more in-depth face-to-face interaction around tasks that are more cognitive in nature. In general, students in our study felt that administrative tasks and course registration tasks did not require extensive instruction from advisors; these tasks were also convenient to complete online. Indeed, students emphasized the logistical benefits of registering from home instead of having to come to campus to meet with an advisor to complete registration. These findings imply that 
technology-mediated systems are appropriate and would be welcomed by students for systemic supports. Moreover, use of such systems would help to free up advisors' time so that they could take a stronger advising-as-teaching approach and focus more on cognitive advising tasks. Thus, instead of using advising sessions to register students for courses, advisors could meet with students to discuss course selection, engaging students more deeply around rationales for different programs of study and educational next steps.

Our findings suggest that while current technology tools do not independently offer cognitive support that is welcomed or trusted by students, they can enhance the in-person advising experience for these support functions. For example, while students may be somewhat wary of early alert tools that offer personalized feedback on student performance, advisors may use this information for a focused discussion of student strengths and academic and vocational decision-making.

Our findings also suggest that students feel that advising technologies can empower them to participate more actively during in-person sessions with advisors. Online education planning tools, for example, can make the complex task of comparing different educational pathways feasible by offering the necessary information in a user-friendly format; students can then do some pre-planning and exploration, allowing them to arrive at advising sessions with questions in mind for the advisor. When used in this way, technology tools can help facilitate the advisingas-teaching approach that students seek but that institutions find difficult to offer, given their often-severe resource constraints.

Our findings also offer insights for the design of technology-mediated affective support. Although affective support does not require extensive instruction, students in need of such support still seek the feedback and interaction that is characteristic of the advising-as-teaching approach. The student perspectives shared in this study suggest that technology used for affective support-and, in particular, the early alert system-may be more effective for students struggling academically if it delivers messages using an encouraging tone. Students in our study preferred early alert messages that asked them to consider why they were struggling academically and then directed them to resources or feedback that was tailored to their response; according to students, when framed in this way, early alert messages did not sound critical and retained a more personal and interactive quality. Colleges and technology providers may therefore want to consider how to approximate advising-as-teaching interactions when designing messages that aim to encourage students and promote their self-efficacy.

In sum, while they may be effective in isolation for systemic support and a potentially useful aid for affective support, our findings suggest that advising technology tools cannot supplant traditional advising experiences. Students seek the interactive relationship with an advisor characteristic of the advising-as-teaching approach, especially for tasks that are more cognitively complex, such as multi-semester course planning. Institutions reforming advising services with a technology-mediated approach would therefore be wise to design a system that maintains in-person cognitive support for students.

Our study is an important first step in unpacking student attitudes toward technologymediated systems for advising. However, our study is limited in a number of ways. The students in our sample are not entirely representative; full-time students in our sample, in particular, are 
overrepresented. Moreover, the nature of our data does not allow us to disaggregate our sample into meaningful student subgroups. Finally, our study does not explore the relationship between technology-mediated advising and student outcomes.

Additional research that addresses these limitations and further explores the use of technology in higher education support services is necessary. As a next step, for example, researchers may want to consider variation in preferences across different types of students. Especially in the context of broad-access colleges, which serve students from a wide range of backgrounds, students likely bring different perspectives to this topic. In particular, researchers may want to consider more focused attention on part-time students, given their large representation at broad-access colleges. Understanding differences in preferences across different types of students (such as part-time compared with full-time students) can further illuminate how technology tools in higher education may be perceived in distinct and nuanced ways, allowing for more effective implementation of these resources. Our analysis suggests that technology has great potential as a supplement to in-person advising resources and merits additional exploration to optimize its potential.

\section{References}

Appleby, D. C. (2008). Advising as teaching and learning. In V. N. Gordon, W. R. Habley \& T. J. Grites (Eds.), Academic advising: A comprehensive handbook (2nd ed., pp. 85-102). San Francisco, CA: Jossey-Bass.

Arnold, K. E., \& Pistilli, M. D. (2012, April). Course signals at Purdue: Using learning analytics to increase student success. Proceedings of the 2nd International Conference on Learning Analytics and Knowledge, 267-270.

Aud, S., Hussar, W., Johnson, F., Kena, G., Roth, E., Manning, E., ... Zhang, J. (2012). The condition of education 2012 (NCES Report No. 2012-045). Washington, DC: U.S. Department of Education, Institute of Education Sciences, National Center for Education Statistics.

Bambara, C. S., Harbour, C. P., Davies, T. G., \& Athey, S. (2009). Delicate engagement: The lived experience of community college students enrolled in high-risk online courses. Community College Review, 36(3), 219-238.

Bettinger, E. P., \& Baker, R. B. (2014). The effects of student coaching: An evaluation of a randomized experiment in student advising. Educational Evaluation and Policy Analysis, 36(1), 3-19. doi: 10.3102/0162373713500523

Blumenstyk, G. (2015). American higher education in crisis? What everyone needs to know. New York, NY: Oxford University Press.

Bound, J., Lovenheim, M. F., \& Turner, S. (2012). Increasing time to baccalaureate degree in the United States. Education, 7(4), 375-424. 
Crosta, P. M. (2014). Intensity and attachment: How the chaotic enrollment patterns of community college students relate to educational outcomes. Community College Review, 42(2), 118-142. doi: 10.1177/0091552113518233

Doyle, W. R. (2010). Open-access colleges responsible for greatest gains in graduation rates (Policy Alert). San Jose, CA: National Center for Public Policy Higher Education.

Esposito, A., Pasquini, L. A., Steele, G., \& Stoller, E.. (2011). A world of tomorrow: Technology and advising. In J. E. Joslin \& N. L. Markee (Eds.), Academic advising administration: Essential knowledge \& skills for the 21st century (Monograph No. 22) (pp. 261-274). Manhattan, KS: National Academic Advising Association.

Felton, E. (2014, December 4). White House summit calls for using data to boost graduation rates. The Hechinger Report. Retrieved from http://hechingerreport.org/content/white-house-summit-calls-using-data-boost-graduationrates_18317/

Gaines, T. (2014). Technology and academic advising: Student usage and preferences. NACADA Journal, 34(1), 43-49.

Goodman, J., Hurwitz, M., \& Smith, J. (2015). College access, initial college choice and degree completion (NBER Working Paper No. 20996). Cambridge, MA: National Bureau of Economic Research.

Grubb, W. N. (2006). "Like, what do I do now?” The dilemmas of guidance counseling. In T. Bailey \& V. S. Morest (Eds.), Defending the community college equity agenda (pp. 195222). Baltimore, MD: Johns Hopkins University Press.

Hornak, A. M., Akweks, K., \& Jeffs, M. (2010). Online student services at the community college. New Directions for Community Colleges, 2010(150), 79-87.

Jaggars, S. S. (2014). Choosing between online and face-to-face courses: Community college student voices. American Journal of Distance Education, 28(1), 27-38.

Jaggars, S., \& Fletcher, J. (2014). Redesigning the student intake and information provision processes at a large comprehensive community college (CCRC Working Paper No. 72). New York, NY: Columbia University, Teachers College, Community College Research Center.

Joslin, J. (2009). Voices from the field: Veteran advisors. NACADA Journal, 29(2), 68-75.

Junco, R. (2010, September). Using emerging technologies to engage students and enhance their success. Academic Advising Today. Retrieved from https://www.nacada.ksu.edu/Resources/Academic-Advising-Today/View-Articles/UsingEmerging-Technologies-to-Engage-Students-and-Enhance-Their-Success.aspx 
Karp, M. M. (2011). Toward a new understanding of non-academic student support: Four mechanisms encouraging positive student outcomes in the community college (CCRC Working Paper No. 28, Assessment of Evidence Series). New York, NY: Columbia University, Teachers College, Community College Research Center.

Karp, M. M. (2013). Entering a program: Helping students make academic and career decisions (CCRC Working Paper No. 59). New York, NY: Columbia University, Teachers College, Community College Research Center.

Karp, M. M., \& Bork, R. H. (2012). “They never told me what to expect, so I didn't know what to do": Defining and clarifying the role of a community college student (CCRC Working Paper No. 47.) New York, NY: Columbia University, Teachers College, Community College Research Center.

Karp, M. M., O’Gara, L., \& Hughes, K. L. (2008). Do support services at community colleges encourage success or reproduce disadvantage? An exploratory study of students at two community colleges (CCRC Working Paper No. 10). New York, NY: Columbia University, Teachers College, Community College Research Center.

Leonard, M. J. (2008). Advising delivery: Using technology. In V. N. Gordon, W. R. Habley \& T. J. Grites (Eds.), Academic advising: A comprehensive handbook (2nd ed., pp. 292306). San Francisco, CA: Jossey-Bass.

Low, L. (2000). Are college students satisfied? A national analysis of changing expectations (New Agenda Series ${ }^{\mathrm{TM}}$ ). Indianapolis, IN: USA Group Foundation.

Lowenstein, M. (2005). If advising is teaching, what do advisors teach? NACADA Journal, 25(2), 65-73.

Moneta, L. (2005). Technology and student affairs: Redux. New Directions for Student Services, 2005(112), 3-14.

Moore, M. G. (1993). Theory of transactional distance. In D. Keegan (Ed.), Theoretical principles of distance education (pp. 22-38). New York, NY: Routledge.

Noonan, J., \& Stapley, J. C. (2015, March). The demise of in-person academic advising is nowhere in sight! Academic Advising Today. Retrieved from https://www.nacada.ksu.edu/Resources/Academic-Advising-Today/View-Articles/The-Demiseof-In-Person-Academic-Advising-is-Nowhere-in-Sight!.aspx

Oblinger, D. (2005). Leading the transition from classrooms to learning spaces. Educause Quarterly, 1, 7-12.

Phillips, E. D. (2014). Improving student success using technology-based analytics. Diversity and Democracy, 17(1). Retrieved from http://www.aacu.org/diversitydemocracy/2014/winter/phillips 
Smith, C. L., \& Allen, J. M. (2006). Essential functions of academic advising: What students want and get. NACADA Journal, 26(1), 56-66.

Stephens, D. (2007). Literature review: Technology investment needs of students and faculty at community colleges. Olympia: WA: Washington State Board for Community and Technical Colleges. Retrieved from http://sbctc.edu/docs/strategicplan/LiteratureReview.pdf

Tait, A. (2000). Planning student support for open and distance learning. Open learning, 15(3), 287-299.

U.S. Department of Education (n.d.). White house initiative on historically black colleges and universities. Retrieved June 22, 2015 from http://www.ed.gov/edblogs/whhbcu/one-hundred-and-five-historicallyblack-colleges-and-universities/

U.S. Department of Education, Institute of Education Sciences, National Center for Education Statistics. (2012). IPEDS Data Center [Data file]. Retrieved from https://nces.ed.gov/ipeds/datacenter/login.aspx

Xu, D., \& Jaggars, S. S. (2013). Adaptability to online learning: Differences across types of students and academic subject areas (CCRC Working Paper No. 54). New York, NY: Columbia University, Teachers College, Community College Research Center.

Yanosky, R. (2014). Integrated planning and advising services: A benchmarking study. Louisville, CO: EDUCAUSE Center for Analysis and Research. 